\title{
Lei suntuária de Valladolid de 1258: a aparência e a moda para as mulheres, os judeus e os mouros
}

\author{
Valladolid sumptuary law of 1258: appearance and fashion for \\ women, Jews and Moors
}

\begin{abstract}
Thaiana Gomes Vieira ${ }^{1}$
${ }^{1}$ Historiadora e Professora de história formada pela Universidade Federal do Rio de Janeiro e Mestre em Artes, Cultura e Linguagens, formada pela Universidade Federal de Juiz de Fora. Atualmente, doutoranda em Design de Moda na Universidade da Beira Interior sob orientação da Professora Doutora Madalena Pereira. Contato: thaianavieira@hotmail.com.
\end{abstract}

Recebido em 30 de março de 2021; Aceito em 27 de junho de 2021.

DOI: $10.12957 /$ nearco.2021.58798

\section{Resumo}

O período da Baixa Idade Média é fecundo em normatividades e é quando surge a moda. As vestimentas são, nesse momento, representações sócio-políticas e as leis suntuárias reconhecem e registram as condições dos habitantes da comunidade. O presente trabalho tem como objetivo principal verificar quais eram as motivações da instituição monárquica de Valladolid ao legislar sobre as roupas no ano de 1258.

Palavras-chave: Moda. Leis suntuárias. Valladolid.

\begin{abstract}
The period of the Low Middle Ages is fruitful in regulations and that's when fashion appears. At that time, the garments are socio-political representations, and the sumptuary laws recognize and record the conditions of the community's inhabitants. The present work has as main objective to verify what were the motivations of the monarchical institution of Valladolid when legislating about clothes in the year 1258.
\end{abstract}

Keywords: Fashion. Sumptuous Laws. Valladolid.

\section{Introdução}

As modificações ocorriam em diversos âmbitos da sociedade, e também no vestuário. O desenvolvimento têxtil afetou diretamente a habitação e o traje, transformando-os. A partir dos progressos nesse segmento foi possível a elaboração de diversas qualidades de panos, inclusive cada cidade possuía uma especialidade, um 
tecido que somente ela conhecia o fabrico e sobre o que guardava segredo. Além disso, razões estéticas e psicológicas também justificam a alteração, por exemplo, do vestuário dos séculos XII a XV, que acompanhou a transformação dos estilos artísticos. ${ }^{2} \mathrm{~A}$ moda em seu sentido de variedade surge a partir das novas condições da produção; a expansão demográfica; o aumento da riqueza coletiva; o desenvolvimento da vida urbana, a intensificação do comércio à distância e o consequente contato entre povos; o surgimento da burguesia; o aparecimento da noção de indivíduo, especialmente a partir do século XII.

O fenômeno moda também influenciou as cidades ocidentais. A lã, que foi a principal matéria-prima para a elaboração das roupas, sendo, inclusive, exportada, abriu espaço também para a seda, as peles, os metais, entre outros materiais. As cidades apesentavam-se como centros de produção e comércio, nas quais se desenvolveram os ofícios relacionados à moda, tais como vendedores de tecidos, costureiros, fabricantes de meias, sapateiros, chapeleiros, fabricantes de aviamentos e alfaiates. (FOGG, 2013, p. 42)

Como anteriormente apontado, no século XIV, a roupa apresentou algumas diferenças em relação ao século anterior e nesse momento o homem tinha um visual que sobressaía em relação ao feminino. A roupa masculina encurta e ajusta bruscamente, ao menos aos olhos dos defensores da tradição (BRAUDEL, 2005, p. 286). Elas eram para os contemporâneos, segundo Braudel, "tão curtas e tão estreitas que deixam perceber o que o pudor manda ocultar" (BRAUDEL, 2005, p. 286). O vestuário feminino apresentou um desenvolvimento menos acentuado. O que acontece é que enquanto a silhueta do homem atual se desenhava no século XIV a da mulher permaneceu enraizada em uma tradição que impediu sua transformação rápida. Religião, pudor, recato podem ter condicionado essa lenta transformação (MARQUES, 2010, p. 73).

Ainda durante o século XIV, as roupas das camadas privilegiadas ganharam muitos enfeites e acessórios, como botões e cintos ornamentados ouro, prata ou com pedras preciosas. Os tecidos também variavam de acordo com a camada social, de modo que as cores mais pigmentadas e os tecidos mais finos eram permitidos apenas às 
camadas altas. E os tecidos crus, mais brutos, sem tantos adornos ou cores eram conferidos às camadas baixas.

Estudar sobre a moda é debruçar sobre um fenômeno completo e complexo. 0 historiador Daniel Roche aponta que "A indumentária, mais do que qualquer elemento da cultura material, incorpora os valores do imaginário social e as normas da realidade vivida; é o campo de batalha obrigatório do confronto entre a mudança e a tradição." (ROCHE, 2000 p. 262).

Os caminhos para estudar moda na Idade Média são: literatura, imagens, leis e artefatos. A literatura aponta aspectos da aparência e vestimentas, porém são pouco descritos de forma mais detalhada. As imagens trazem as roupas e adornos, mas muitas vezes são representações alegóricas e possuem muitos outros fatores determinantes que dificultam a análise da sociedade por meio das vestimentas.265 Os artefatos seriam instrumentos bastante completos para esse objetivo, entretanto pouquíssimos resistiram às ações do tempo. As leis possuem o empecilho de verificar sua eficácia, contudo aparece como fonte mais completa para a realização do estudo da sociedade baixo medieval por meio do que normaliza com relação às roupas, adornos, tecidos, matéria-prima e trabalhadores.

As leis, que trazem regras sobre consumo de elementos de moda, que analisaremos estão presentes nas Atas das cortes dos Antigos Reinos de Leão e Castela, publicadas pela Real Academia de la Historia, impressas pela Imprenta y Estereotipia de M. Rivadeneyra, em Madrid, em 1861 e 1863 sob o título de Cortes de los antigos reinos de Leon y de Castilla e possui cinco tomos.

265 Como por exemplo, as pinturas que muitas vezes apresentam diversos itens da aparência mesmo que o sujeito representado não os possuísse. Faziam isso com o objetivo de retratar poder, riqueza e associar o protagonista da representação imagética a alguma elevação social, política e econômica, mesmo que muitas vezes ela não tivesse relacionada à aparência. O que, por sua vez, reforça a ideia de que possuir itens de vestimenta e adorno é um luxo, permitido àqueles sujeitos poderosos. Tanto quanto o fato de estarem sendo retratados. Nesse momento pintavam-se figuras religiosas e figuras alegóricas, comumente aqueles que encomendaram as figuras bíblicas e reis e nobres. Em resumo, muitas vezes as peças de aparência são retratadas mais por seu simbolismo de poder e riqueza do que propriamente por sua utilização por aqueles sujeitos da imagem, o que é inviável para uma análise complexa da utilização das peças nas sociedades baixo medievais. 


\section{Conceitualização}

A palavra "moda" possui tantas aplicações, é utilizada de tantas formas e de modos tão amplos que é preciso definir o que, extamente, estamos considerando quando anunciamos moda nesse trabalho. Denise Pollini aponta que "A moda está muito mais relacionada a um conjunto de fatores, a um sistema de funcionamento social, do que especificamente às roupas, que são apenas a ponta desse iceberg." (POLLINI, 2007, p.17).

A moda é, em sentido geral, a adoção de uma postura, apreensão de uma realidade, de um comportamento, de uma identidade. A roupa marca, representa e comunica algo. Considerando o contexto e os dispositivos de uma época, aquela permite a produção e a compreensão do cenário, configura uma linguagem específica, e, por fim, a percepção de uma encenação da realidade. Moda é, neste caso, uma intervenção que organiza e hierarquiza o mundo e as relações sociais; é uma linguagem de um grupo e de uma época, materializa e oferece sentido aos sujeitos históricos e concretiza um estilo de ser e de estar numa sociedade. Sublinhamos que a moda não consegue ser, efetiva e longamente, privativa de um grupo. Ao tornar-se pública, ao ganhar as ruas, ela pode ser partilhada por outros grupos ou sofre uma releitura. Esta valoriza uma "distância" entre os sujeitos, e ao realizar tais processos ela significa e ressignifica os sentidos.

Muitas são as transformações ocorridas na Baixa Idade Média, mas a inovação no aspecto social interfere em diversos outros segmentos. Surge uma nova camada, a burguesia. ${ }^{266}$ Eles viviam nas cidades e constituíam os núcleos principais de atividade econômica e cultural. Nos centros urbanos, o contato com diversos grupos é direto, real e cotidiano. Assim, a emulação, profissional, alimentar, postural, de linguagem e também de vestuário, acaba acontecendo. Sobre o que António Marques destaca:

Ao sair da igreja, ao tomar assento na assembleia camarária, ao participar nas festividades da sua cidade, o burguês sentia sempre o desejo de superar o seu concidadão. Pretendia chamar a atenção sobre si através da qualidade de

\footnotetext{
266 Destacamos que nesse momento é uma burguesia incipiente, não como teremos nos séculos XVI e XVII. De qualquer forma, nesse período ela incomoda demais a aristocracia e quer se distanciar das camadas baixas, então se estabelece com características próprias.
} 
tecido que envergava e da forma como o talhava. Queria, em suma, mostrarse diferente, mais rico, e mais belo (MARQUES, 2010, p. 45).

Durante séculos, o traje de moda permaneceu um consumo luxuoso e prestigioso confinado às classes nobres e o vestuário respeitava a hierarquia das condições. Com a emulação insistente dos burgueses com relação às modas da aristocracia, a elite decide elaborar normatizações que os impeça de ter aparência semelhantes. As leis suntuárias proibiam as camadas baixas de se vestirem como os nobres. Segundo Diana Crane “...leis suntuárias especificavam os tipos de material e ornamento que podiam ser usados por membros de diferentes classes sociais" (CRANE, 2013, p.24). Fica claro, desde esse período inicial (século XIV principalmente), que a moda já revelava seus traços sociais e estéticos característicos, mas apenas para grupos muito restritos que monopolizavam o poder de criação e iniciativa.

Segundo Gilles Lipovetsky, "Só a partir do final da Idade Média é possível reconhecer a ordem própria da moda, a moda como sistema, com suas metamorfoses incessantes, seus movimentos bruscos, suas extravagâncias." (LIPOVETSKY, 2009. p.24). Desse modo, o que consideramos comumente como moda surgiu no final da Idade Média, particularmente no século XIV, quando apareceu um tipo de vestuário diferenciado para os dois sexos: curto e ajustado para o homem, longo e justo para a mulher (LIPOVETSKY, 2009. p.31). O autor acrescenta: "Se o lugar do aparecimento importante revolução do vestuário é controvertido, sabe-se em compensação que muito depressa, entre 1340 e 1350, a inovação difundiu-se por toda a Europa ocidental." (LIPOVETSKY, 2009. p.32). Foi a partir desse momento que as mudanças começaram, intensificaram e as variações tornaram-se mais correntes em toda a Europa ocidental. Segundo Daniel Roche,

A moda era, portanto, antes de tudo, um ponto de equilíbrio entre o coletivo e o individual, uma maneira de marcar a hierarquia social, ao mesmo tempo fixa e móvel. À medida que floresceram as distinções indumentárias, a fantasia de alguns e o conformismo de outros desencadearam ação defensiva de parte de instituições (a Igreja) ou grupos (a burguesia) que haviam ficado para trás (ROCHE, 2007, p.61). 
Destacamos que essa data (1340-50) marca a difusão da moda pela Europa Ocidental. Antes dessa expansão houve inovações na aparência e vestuário que ocorreram e não foram suficientes para alastrar por toda a Europa, ou seja, aconteceram e ficaram restritas em suas regiões. É desse modo que justifico a utilização de uma lei anterior ao período considerado como o surgimento da moda na Europa.

Na região de Valladolid, antes da data de 1340-50, já havia mudança relevante no vestuário, tanto que houve necessidade de normatizar sobre ela. Entretanto, não foi tão impactante ou tão bem aceita pelos sujeitos das demais localidades a ponto de estender-se por toda a Europa ocidental nesse momento e por esse motivo não marca a difusão da moda. Além disso, ressaltamos que a regulamentação é mais voltada, no que se refere à vestimenta, aos grupos marginalizados: mouros e judeus. Ou seja, não implica necessariamente grandes transformações em termos de moda, mas pratica o objetivo visual de segmentar esses grupos e demarcá-los como marginalizados.

\section{Atas da corte de Valladolid de 1258}

A aparência se altera de modo brusco inicialmente pelo vestuário masculino. Como aponta Braudel,

\footnotetext{
A grande mudança é que por volta de 1350, encurta de uma assentada o vestuário masculino, de maneira escandalosa aos olhos das pessoas sensatas, dos idosos, dos defensores da tradição. (...) Esta roupa justa ao corpo há de durar, e os homens nunca mais andarão de saias compridas. Quanto às mulheres, os corpetes também se apertam, desenham as formas e abrem-se em amplos decotes-outro motivo de censura (BRAUDEL, 2005, p. 286).
}

Nesse sentido, destacamos que não foi sempre que a moda foi associada ao feminino. Logo no momento de surgimento, o fenômeno acometia a homens e mulheres, não de todas as idades, mais recorrentemente aos jovens, porém de ambos os sexos. Inclusive, "os primeiros controlos sumptuários medievais, fixados por Carlos Magno e pelo seu piedoso filho, não prestavam especial atenção ao vestuário ou à ostentação das mulheres." (HUGHES, 1990, p.186). 
Ainda,

os cronistas monásticos do século XII ${ }^{267}$ encontraram sinais de declínio moral não nas roupas alongadas e justas das mulheres, mas antes nos laços apertados e nas caudas exageradas dos homens, cujas cabeleiras caídas e andar afectado completavam uma ameaça travestida aos modelos de um passado marcial. (...) Mas eles apontavam igualmente a invenção de certas modas particularmente odiosas, criadas directamente para a vaidade masculina (HUGHES, 1990, p.186).

A moda somente passa a ser associada ao feminino quando a roupa adquire potencial de significação social. Nesse momento, o tecido e as peças produzidas a partir do mesmo são considerados item de status e, consequentemente, de mobilidade social, com a possibilidade de moldar a distinção política e também entre os sujeitos da comunidade (HUGHES, 1990, p.174). Sobre isso Diane Hughes aponta

As mulheres sentiram-se particularmente vulneráveis à manipulação social que a indumentária permitia, pois, suas marcas visíveis ajudaram a fixar e solidificar uma identidade social necessariamente mais fluida que a dos homens que a concebiam. Quase ao mesmo tempo do auge da produção têxtil dos séculos XII e XIII, ocorreu uma troca que acentuou a ambiguidade de sua posição social e, em consequência, contribuiu a sua dependência referente às distinções e definições da vestimenta: o desenvolvimento de uma ideologia patrilinear de descendência por via masculina. ${ }^{268}$ (HUGHES, 1990, p.175).

Não queremos dizer que a moda acontece apenas em função dos homens. As mulheres usam a aparência para situar seu posicionamento em relação ao seu marido, pai e família. Entretanto, estas também possuem autonomia no seu modo de vestir e utilizar adereços, penteados, lenços e outros complementos vestimentares. Ou seja,

\footnotetext{
267 O trecho destaca um apontamento de moda antes de 1350, momento aproximado do que consideramos o surgimento da moda, mas ressaltamos que isso não interfere na nossa perspectiva. Afinal, não desconsideramos expressões locais antes da segunda metade do século XIV. Esse momento é considerado o surgimento da moda que tem força para expandir por toda a Europa. Antes, houveram algumas, poucas, transformações no vestuário, mas sem grandes impactos fora de sua localidade.

${ }^{268}$ Traduzido pela autora a partir do original: "Las mujeres se sintieron particularmente vulnerables a la manipulación social que la indumentaria permitia, pues suas marcas visibles ayudaron a fijar y solidificar uma identidade social necessariamente más fluida que la de los hombres que la diseñaban. Casi al mismo tempo que el auge de la producción têxtil de los siglos XII y XIII, tuvo lugar um cambio que acentuo la ambiguedad de su posición social y, em consecuencia, contribuyó a su dependência respecto de las distinciones y definiciones de la vestimenta: el desarrollo de uma ideología patrilineal de descendência por vía masculina."
} 
elas conseguem na aparência demonstrar a posição da família e também, em alguma medida, a sua expressão além do previsível.

A principal manifestação dessa mobilidade fluida, principalmente em função da patrilinearidade é momento do casamento, conforme a análise que segue.

Destacamos que a moda medieval não é homogênea. Não se pode considerar que todas as mulheres de um grupo social se vestiam exatamente do mesmo modo, ou que as pertencentes de uma mesma religião usavam as roupas detalhadamente iguais, ou que as trabalhadoras tinham apenas suas peças destinadas ao labor, ou que suas vestimentas festivas fossem iguais às de seus pares. O que percebemos é um determinado padrão para o período e para as camadas sociais mais relevantes, porém as peças variavam de tecidos, cores, ornamentos, dentre outros detalhes. Além do fato de alguns itens particulares inseridos na aparência pelos próprios sujeitos, buscando alguma distinção.

Nesse sentido, optei por ressaltar a lei de 1258 para tratar das mulheres, judeus e mouros, momento que a moda ainda não é considerada como realidade em toda a Europa, para trabalhar justamente com especificidades. Ou seja, mesmo concordando que a moda tenha surgido enquanto sistema posteriormente, julgo relevante destacar expressões anteriores.

\section{Mulheres}

A aparência feminina tem muita relevância no reino de Castela na Baixa Idade Média. É alvo de regulamentações laicas e religiosas voltadas para a comunidade e também religiosa voltada para a coletividade cristã. Ou seja, nesse período muitos documentos foram redigidos preocupados com a imagem feminina, são leis, regras que possuem suas cláusulas referentes à exterioridade, obras de literatura que abordam a temática e discursam sobre possibilidades de manipulação a partir da aparência, dentre outros. 
Mulheres são nesse momento as que mais aparecem retratadas nas leis com relação às vestes suntuosas. Acreditamos que esse fato ocorre porque os homens dessa sociedade demonstram nas mulheres o poder que possuíam; porque havia uma preocupação para que as mesmas não incidissem ou não conduzissem outros sujeitos ao pecado e à infração; ou simplesmente porque elas infringiam as leis com mais frequência que os homens, gerando a necessidade de intensificar as regras.

Para essas mulheres a condição conjugal é superior à sua posição social. Ou seja, a mulher que é casada deve seguir e respeitar a aparência coerente a essa situação, abdicando de muitos itens considerados luxuosos e de moda, ainda que possuam riqueza para usá-los, conforme a lei permite. Inclusive porque a atenção à aparência tem como principal motivação atrair os olhares dos homens para que alcançassem o casamento, função principal da mulher nessa sociedade, seguida da reprodução. Quando as mulheres casavam, o cuidado com a exterioridade deve acontecer para que os maridos não cometessem adultério, mas essa imagem deveria ser comedida, para que atraísse apenas o seu companheiro. Do contrário, o uso de peças belas, adornadas e valorizadas era considerado um insulto, na maioria das vezes, contra a normatização e também um pecado, em resumo, uma dupla infração.

Destacamos um aspecto que segue a lógica anteriormente anunciada,

E quem casar com concubina, no cabelo que não dê mais de sessenta maravedís em panos para seu casamento. E o que casar com viúva que dê sessenta maravedís em panos para seu casamento e o que der mais do que isso que o rei manda, que fique a sua mercê. ${ }^{269}$

Ou seja, a normatização parece empenhada em elaborar um padrão de aparência às mulheres no momento do casamento, especialmente sobre artigos de luxo tão simbólico como o tecido sobre o cabelo.

A preocupação em regulamentar o momento do matrimônio acontece porque esse é um rito social extremamente relevante, uma ferramenta de construção ou

269Traduzido pela autora a partir das Atas da corte de Valladolid de 1258: "Et quien casar con mançeba en cabello que non dé .mas de .LX mr. por pannos pora sus bodas. El el que casare con biuda quel dé .LX. mr. por pannos pora sus bodas e el que mas diere desto que manda el Rey que sea a sua merçerd." 
reconstrução social e política dentro da sociedade (HUGHES, 1990, p.175). Ou seja, pela sua relevância era um momento oportuno para aqueles que quisessem manipular seu lugar na comunidade por meio da aparência, daí serem alvo de regras urbanas.

Rivair Macedo aponta que o cabelo é relevante nas sociedades medievais em diversos aspectos, tanto para o sujeito quanto para a comunidade.

\begin{abstract}
Tal cuidado revela-nos o quanto, na percepção do corpo tida pelos medievais, os cabelos constituíam signo importante da consciência de si e da representação social. Nas sociedades tradicionais havia certa conexão entre o tamanho, o formato e a disposição da cabeleira com regras e tabus de natureza sexual. Em diferentes conjuntos culturais, as mudanças marcadas por penteados são comumente acompanhadas de alterações no status sexual que ocorrem, por exemplo, na puberdade e no casamento (MACEDO, 1998, p. 308).
\end{abstract}

Nesse sentido, o tecido sobre o cabelo é emblemático, pois a mulher jovem poderia mostrar os fios soltos, ou presos, penteados ou com chapéus. Já as mulheres casadas deveriam utilizar um pano sobre a cabeça com a finalidade de cobrir o cabelo, item de sedução feminina, que a partir do ato do matrimônio deixa de ser necessário, e respeitoso, apresentá-lo nas ruas ou na frente de outros. Mulheres dedicadas à vida religiosa também cobriam a cabeça com o intuito de ocultar o cabelo sedutor. Ainda sobre isso Rivair Macedo sublinha as considerações do antropólogo Edmond Leach (1983) e apresenta que

\footnotetext{
nas situações aludidas, em geral o cabelo longo esteve associado simbolicamente à sexualidade não restringida, enquanto o cabelo curto, cabeça parcialmente raspada ou cabelo bem amarrado indicava sexualidade restringida, e a cabeça totalmente raspada, a abstinência sexual (MACEDO, 1998, p. 308).
}

O hábito de utilizar véus sobre a cabeça, ao que as reflexões indicam, é oriundo da cultura muçulmana (BOUCHER, 2010, p. 164). O que é mais relevante é que o tecido sobre a cabeça mantém o ideal de fidelidade e, até certo ponto, castidade, nas duas civilizações. Sobre o que Rivair Macedo destaca:

Dentro dos sistemas simbólicos da Idade Média, o tamanho e a forma da cabeleira podiam indicar aspectos das convenções sociais: solta, tinha forte valor erótico, porém desfeita e desgrenhada indicava tristeza. O modo pelo qual as mulheres dispunham-na revelava seu lugar na família e na sociedade. Com frequência, às jovens solteiras era permitido mantê-la exposta e ligada 
por uma trança, indicação visível de sua disponibilidade para o casamento. As mulheres casadas deveriam mantê-la escondida, discreta, ou então amarrada em duas tranças e coberta por touca ou chapéu, evidenciando desse modo seu compromisso conjugal. (Régnier-Bohler, 1991, p.362; Frugoni, 1993, p. 474-475) (MACEDO, 1998, p. 309).

Diane Hughes aponta a questão da diferenciação moral das mulheres que usam os diferentes tipos de véus. De modo geral, são utilizados para as mulheres casadas, com a intenção de castidade. Porém era utilizado por mulheres não casadas, como a própria lei aponta, como o caso das viúvas, com algumas diferenciações. A autora, por exemplo, destaca que as prostitutas utilizam tipos de lenço sobre a cabeça com cores e tecidos, e consequentemente conotações, bem divergentes das outras mulheres.

No século XIII, os eclesiásticos trataram de criar uma categoria visual de honra feminina insistindo no véu como signo de mulher adequadamente casada, moda que muitos governos urbanos negaram às prostitutas públicas, que deveriam caminhar com o invento de véus de seda transparente, que não escondiam nada, e outros que cobriam demais e emascaravam perigosamente a identidade e status da mulher $^{270}$ (HUGHES, 1990, p. 186).

A intenção é de moralização dessa mulher que deve ser vista pelos outros habitantes da comunidade como perigosa, com a face escondida, ou vista com dificuldade, de qualquer modo, a identificando como ameaçadora. Ou alguém tão desprezível que pode ser vista por todos, quando liberado o uso de véus transparentes. Condição bem diferente das mulheres de condição matrimonial diferente, seja casada ou viúva, que merecem olhar e tratamento respeitosos e condizentes tanto dos homens quanto das demais mulheres.

Os valores que aparecem nos trechos ressaltados da lei aparecem justamente para balizar as quantias gastas com a aparência. As motivações de significação social e demonstrativo de patrimônio da família acabam incentivando o uso de peças valiosas e, consequentemente, muito consumo no âmbito da exterioridade pessoal. Nesse sentido,

\footnotetext{
${ }^{270}$ Traduzido pela autora a partir do original: En el siglo XIII, los eclesiásticos habían tratado de crear uma categoria visual de honor feminino insistiendo em el velo como signo de mujer adequadamente casada, moda que muchos gobiernos urbanosnegaron a prostitutas publica, quienes tenían que caminhar com el invento de velos de seda transparente, que no escondían nada, y otros que cubrían demasiado y enmascaraban peligrosamente la identidad y el status de la mujer.
} 
não é surpreendente que o casamento seja um dos primeiros acontecimentos que a lei urbana se volta com a intenção de normatizar. (HUGHES, 1990, p.186)

São muitos os itens que podem ser adquiridos para demonstrar poder, riqueza e destaque. Por exemplo: batas, véus, joias, sapatos, bolsas, mangas, casacos, chapéus, e muitos outros acessórios menores. Isso faz com o que a lei fique cada vez mais complexa, em resposta à sociedade que vai incrementando o significado social de todos esses elementos, materiais que os compõem, valores de presentes aos noivos (que também dá relevância e simbologia àqueles que oferecem), dentre outros aspectos.

Essas vestes tão elaboradas não podem ser sempre desmanchadas para feitura de novas peças para as outras gerações. Isso causa um desperdício de tecidos, de materiais, de mão de obra para confecção das roupas, de metais preciosos e até ouro, que muitas vezes compunham as vestimentas, e consequentemente, desprendiam e dissipavam muita verba.

Objetivando manter recursos dentro do patrimônio familiar, e perder menos valores com esses movimentos da moda de substituição em curto tempo de peças e de não reutilização de todos os materiais custosos, os homens da cidade acabam por limitar nas leis valores a serem gastos em cada peça segundo as condições de provimento, atuação e camada social. Sobre o que Diane Hughes aponta:

É certo que a necessidade de atender às exigências cada vez mais volúveis da moda alentou às mulheres a incluir rolos de tela sem cortar entre os elegantes vestidos de seu enxoval de noiva, também é verdade que levou aos maridos que estavam na legislatura a declarar fora da lei as novas modas em gorgueras, corsés e mangas que cediam à pressão social e mantinham suas esposas ao último grito da moda, ameaçavam consumir a riqueza familiar no término da duração do matrimónio. ${ }^{271}$ (HUGHES, 1990, p.177)

271Traduzido pela autora a partir do original: "Si bien es certo que la necesidad de atender las exigências cada vez más veleidosas de la moda alento a las mujeres a incluir rolos de tela sin cortar entre los elegantes vestidos de su ajuar, tambíen es verdade que llevó a los maridos que estaban en la legislatura a declarar fuera de la lei las nuevas modas em gorgueras, corsés yy mangas que, si cedian a la presión social y mantenian a sus esposas al último grito de la moda, amenazaban com consumir la riqueza familiar em el término de duración del matrimónio." 


\title{
Judeus
}

Judeu, de acordo com o dicionário Priberam da Lingua Portuguesa 272 é quem professa a religião judaica; relativo à tribo ou ao reino de Judá; o mesmo que israelita; indivíduo que viaja com muita frequência, que não se fixa num lugar; agiota, usuário. Todas essas características podem referir-se ao sujeito que pertence à religião judaica, pois ela possui diversas implicações e possibilidades. Mas o fato é que esse grupo possui estereótipo marcado mesmo nos dias atuais.

Segundo Henry Loyn, a história desse grupo, os judeus, inicia na Antiguidade e a "Idade Média devia ser corretamente interpretada como um episódio vital na Diáspora, 273 ou dispersão, dos judeus, no decorrer da qual eles passaram a ser um povo predominantemente europeu e urbano." (LOYN, 1990, p. 345) O mesmo autor, explica:

\begin{abstract}
A perda de um reino judeu significou que a responsabilidade pela sobrevivência do Judaísmo e da consciência de uma herança judaica ficou com os grupos dispersos que se mantiveram leais ao sentimento de história judaica consubstanciado no Antigo Testamento e na língua hebraica, e ao ritual judeu, especialmente a circuncisão masculina e a guarda do sábado (sabbath) (LOYN, 1990, p. 345).
\end{abstract}

Em resumo, esse grupo possui em sua trajetória a tradição de estar unidos e de viver em conformidade com lealdade aos seus pares principalmente e com o Antigo Testamento. Essas características surgem no momento de maior dificuldade que essa comunidade passou, que foi no momento da perda do reino. Nesse sentido, os sujeitos, sem domínios de terra, iniciam sua peregrinação por diversas regiões do mundo buscando um local para habitar, praticar suas crenças, costumes e viver em sociedade.

Desse modo, os judeus foram se alocando em reinos que eram habitados por pessoas cristãs na maior parte da demografia. Ou seja, eram encarados inicialmente como diferentes, posteriormente como aquele que não é cristão e nesse momento, começavam os julgamentos e condenações que a cristandade realizava com o grupo

272 Judeu, in Dicionário Priberam da Língua Portuguesa. Disponível em: https://www.priberam.pt/dlpo/judeu Acesso em 15-03-2021.

\footnotetext{
${ }^{273}$ Separação de um povo ou de muitas pessoas, por diversos lugares, geralmente causada por perseguição política, religiosa, ética ou por preconceito. Diáspora, in Dicionário online de Português. Disponível em: https://www.dicio.com.br/diaspora/ . Acesso em 07 de março de 2021.
} 
religioso divergente. No que se refere à Idade Média destacamos também o que o historiador especialista nesse grupo religioso, Sergio Feldman, aponta:

O judeu é parte de um entendimento diferente. A sociedade medieval é regida pelo religioso e cultural e este permeia as relações sociais e políticas. Os judeus foram inseridos no mundo cristão antes de assumirem uma função socioeconômica e além desta. Fazem parte da finalidade da História definida e delineada pelos Padres da Igreja nos séculos 4 e 5 (FELDMAN, 2015, p. 4).

Sublinhamos que os judeus são considerados como diferente dentro da noção de unidade cristã, ou seja, como eles não pertencem a essa consubstanciação são tidos como o elemento distinto. A questão é que mesmo com religião diferente e todo o exílio que isso poderia acarretar, esse grupo possui habilidades bastante úteis dentro das sociedades medievais, como trataremos a seguir. E na maioria das vezes essas aptidões são aproveitadas, mas esses sujeitos são marcados conforme sua condição religiosa. Ou seja, é uma incorporação social no sentido de que esse grupo faz parte daquela sociedade, porém são colocados à margem da sociedade cristianizada, o que acaba os excluindo e conferindo-os uma realidade de sobrevivência excludente.

No que se refere à história da península Ibérica, os judeus estiveram presente em grande parte de seus momentos, senão todos eles, e permanentemente em minoria comparado aos outros grupos. Sobre isso Sergio Feldman aponta:

Na Península Ibérica a presença judaica alternou alguns momentos. Um momento de proteção imperial, matizado por uma Igreja militante e ativa no baixo Império. Dois momentos sob os reinos bárbaros: sob os reis visigodos arianos, ocorre certa indiferença e uma tolerância relativa; sob os reis visigodos católicos os judeus são banidos e exilados do reino visigótico. Os que permanecem devem se converter ao Cristianismo. Segue-se uma severa e aguda perseguição aos conversos, acusados de criptojudaísmo ${ }^{274}$ e que culminou numa legislação intolerante e numa aparente perseguição aos judeus batizados à força e a seus descendentes através do século sétimo e que se encerra em 711 com a invasão muçulmana. (FELDMAN, 2007, p. 4)

274 “Ato ou costume de judaizar fora dos alhares da sociedade. Tradição criada pelos cristãos novos após
o estabelecimento da inquisição, na Espanha em 1492 e em Portugal 1496. O praticante
de criptojudaísmo é denominado na península ibérica e América Latina de Marrano ou Chueta."
$\begin{array}{llll}\text { Criptojudaísmo } & \text { in } & \text { Dicionário } & \text { Informal. }\end{array}$ Criptojudaísmo $\quad$ http://www.dicionarioinformal.com.br/criptojuda\%C3\%ADsmo/ Acesso em: 15 de março de 2021. 
Durante o período da Reconquista ${ }^{275}$ a situação se altera um pouco, inclusive pelo caráter do longo tempo de guerra. Sublinhamos novamente o historiador sobre esse momento:

Na prática foi uma luta de setecentos anos com longos períodos de paz e de interação entre cristãos, muçulmanos e judeus. Na memória coletiva se trata de um combate secular e enraizado na identidade cristã. Fica claro que o matiz ideológico influencia a discussão. A guerra esteve entremeada por longos períodos de vida cotidiana em locais nos quais cristãos, muçulmanos e judeus viveram lado a lado e tiveram ora convivência respeitosa, ora os conflitos comuns ao cotidiano. Não ocorreu uma guerra contínua por sete séculos (FELDMAN, 2007, p. 3).

\section{Entretanto o que é mais relevante nesse momento é que}

em meio a guerras e tensões, debates e tentativas de conversão do 'outro', seja por meio de pregação, seja por meio de conversões forçadas, a tolerância era limitada e matizada pelos interesses ora da Igreja, ora da Coroa, ora dos componentes de setores sociais envolvidos com o 'outro' (FELDMAN, 2007, p. 3).

Ou seja, o judeu é considerado outro, estigmatizado, marginalizado, mas em alguma medida ele se faz necessário naquela comunidade, como consideram as maiores autoridades, a Coroa e a Igreja, que passam a manipular suas grandes ações e atividades conforme seus interesses.

Sobre isso o especialista Sergio Feldman aponta

A necessidade dos judeus para a expansão dos reinos cristãos se configura como inevitável. Seu papel nas finanças, no comércio, na medicina e especialmente na administração pública é quase óbvio e compreensível, visto não haverem letrados, salvo clérigos. A fragilidade cultural dos reinos do norte diante do inimigo muçulmano somada ao vazio demográfico gera a busca de elementos que colonizem as regiões que começam a ser ocupadas e ajudem na organização da sociedade. Os reis desenvolvem uma

275 Nome dado ao processo pelo qual, a partir do século XI, as comunidades cristãs da Espanha reconquistaram os territórios perdidos para os muçulmanos nas décadas imediatamente seguintes a 711. As principais datas decisivas são: a recuperação de Toledo em 1085; a formação do reino de Portugal e a conquista de Lisboa (1148); a batalha de Navas de Tolosa (1212) e a subseqüente extensão da autoridade cristã a Sevilha e Córdova. No final do século XIII, somente o reino de Granada ainda estava em mãos muçulmanas, assim permanecendo até 1492. As fontes literárias tendem a romancear e simplificar excessivamente a Reconquista em sua interpretação da história hispânica, vendo-a como uma longa Cruzada desde o reinado de Carlos Magno até o final da Idade Média. A realidade, porém, era muito diferente, e a Reconquista deve ser interpretada no contexto de uma interação complexa de povos cristãos, muçulmanos e judeus - que fez da Espanha uma das mais importantes fontes de vida intelectual e cultural na Idade Média central. LOYN, Henry Royston. Op. Cit.. p. 482. 
dependência aguda da funcionalidade judaica em cargos de administração, finanças e nos cargos diplomáticos. A maioria absoluta dos judeus é letrada, e geralmente domina cerca de três idiomas: hebraico, árabe e o romance (castelhano arcaico ou latim vulgar). Por vezes associam a esses dotes outros, que thes coloca como adequados a ajudar os reis por saberem que só eles podem garantir sua integridade física e os direitos legais desses servidores considerados infiéis pelo clero e pelos cristãos. No âmbito da sociedade, somente os reis podem proteger os membros da comunidade judaica, da violência dos nobres e do povo 'comum' e da sanha do clero regular e secular (FELDMAN, 2007, p. 5).

Provada a necessidade do judeu na comunidade ibérica medieval, tanto no âmbito cultural, social, econômico e até religioso, vamos a sua exclusão social. Esse grupo religioso, possui características muito específicas em diversos segmentos e que na maioria das vezes distingue largamente dos demais habitantes de qualquer camada social. Assim, já há uma dificuldade de inserção espontânea. Ao que se soma o olhar dos cristãos os sinalizando como "outro" e apontando e destacando suas diferenças. A competência dos judeus nos assuntos administrativos e econômicos são, depois das motivações religiosas propagadas pelo cristianismo, os estímulos mais fortes para a segregação. Conforme Sergio Feldman descreve:

Assim os judeus são alvo de ódio visceral de certos setores sociais: os poucos e frágeis burgueses que ocupam o comércio e o artesanato e dependem do financiamento de alguns judeus e sofrem a concorrência de outros; o clero secular inculto e preconceituoso que deplora a inserção social dos judeus na corte; de maneira mais ampla e competente o clero regular, em especial as ordens mendicantes do século 13 que se organizarão numa campanha antijudaica; e a nobreza, ora endividada com os judeus e ora em choque com o monarca e que percebe que o aumento do poder da Coroa se dá através do apoio judaico (FELDMAN, 2007, p. 7).

Assim, nesse contexto de necessidade desse grupo, de demarcação e de certo ódio com relação aos judeus, temos no artigo 26 da lei em questão:

Que nenhum judeu não traga pena branca nem cendal de nenhum modo, nem siella de barba dourada nem prateada, nem calças bermeias nem pano tingido nenhum, senão pres ou bruneta preta ou inglês ou enssay negro, fora aqueles que o Rei mandar.276

276Traduzido pela autora a partir das Atas da corte de Valladolid de 1258: "Que ningun judio non traya pena blancanin çendal em ninguna guisa, nin siella de barba dorada nin argentada, nin calças bermeias ninpanno tinto ninguno, sinon pres o bruneta prieta o inglês o enssay negro, fuera a aquellos quelo el Rey mandare." 
Nesse trecho está definido que nenhum judeu, poderia usar tecidos e adornos luxuosos. Ou seja, a normatização recai sobre a aparência do personagem. Acerca do que Rivair Macedo destaca a relevância:

A distinção pelo vestuário era o sinal exterior de uma sanção moral dirigida a indivíduos tidos como perniciosos aos membros da sanior pars da sociedade. No caso em tela, tanto os judeus quanto os muçulmanos que viviam em território cristão eram considerados infames desde o nascimento, sofrendo por isso uma série de limitações de natureza jurídica que os rebaixavam perante a estima coletiva e afetavam sua_publica fama, quer dizer, sua imagem social. A estes estava vedado o acesso a funções públicas ou a obtenção de honras, não lhes era reconhecido valor ao juramento e seu testemunho tinha pouca ou nenhuma credibilidade como meio de prova. Carregavam consigo o estigma da indignidade social, sendo portadores daquilo que os especialistas em história do direito qualificam de_infamia facti. (MACEDO, 2003, p. 5)

O artigo impõe que nenhum judeu, de nenhuma condição de trabalho, idade, sexo ou família, utilize os elementos ressaltados. Ou seja, a condição de judeu se sobrepõe a qualquer outra situação ou função dele na sociedade. A proibição ao luxo possivelmente acontece, pois eles possuíam, na maioria das vezes, recursos para adquirir esses apetrechos e panos. E cristão nenhum ficava satisfeito de ver sujeito de grupo tão odiado com aparência mais satisfatória que a sua própria.

Além disso, destacamos o trecho final do artigo 26 da lei em questão "fora aqueles que o Rei mandar". Esse fragmento indica que não poderiam usar os elementos abordados anteriormente, exceto quando o rei mandar utilizar algo. Pensamos que aqui seja uma abertura para os signos de distinção que aparecem inicialmente no IV Concílio de Latrãono século XIII, 1213 especificamente.

O referido artigo canônico determinava a obrigatoriedade do uso de trajes especiais, mas era omisso quanto ao aspecto que deveriam ter. Para os judeus, o sinal infamante variou em detalhes e cores, consistindo no porte de uma roda de feltro amarelo costurada nas vestes que lhes cobria o peito ou o ombro (roelle, rouelle, rotela), de uma estrela amarela, ou então no uso de um chapéu cônico. (MACEDO, 2003, p. 7)

Não vou adentrar na questão do concílio para não desvirtuar de nosso tema e objetivos. Mas cabe ressaltar que esse trecho no concílio277 se refere à necessidade de 
distinguir os sujeitos visualmente, pois em algumas localidades judeus, cristãos, mouros estão todos vestidos iguais, sem qualquer distinção. Desse modo, não se tem como saber qual sujeito pertence a qual grupo dificultando a adequação do comportamento. (MACEDO, 2003, p. 6)

Porém, o que acontece, conforme Rivair Macedo aponta, é que na Península Ibérica houve resistência em adotar esse artigo.

Em Aragão, já em 22/12/1228 Jaime I, o Conquistador, obrigou os judeus a usar sinal distintivo em público, mas em Castela Fernando III mostrou alguma relutância em fazer o mesmo, uma vez que parte da comunidade judaica ameaçava abandonar o reino e migrar para terras sob domínio islâmico, tal a indignação que sentiram. (MACEDO, 2003, p. 7)

E ainda:

\begin{abstract}
A pressão clerical era recorrente nos decretos papais e nas decisões emanadas dos concílios peninsulares. Em 1239 Gregório IX, à pedido dos prelados de Córdova e Baeza, mandou que o bispo de Córdova obrigasse os judeus ao uso dos sinais. A mesma decisão aparece nas atas do Concílio de Valladolid, em 1228, nas do Concílio de Zamora em 1313, e nas do Sínodo de Alonso de Fonseca celebrado em Ávila em 10/09/1481, onde aos judeus era prescrito o uso público de sinais vermelhos, aos mouros, capuzes amarelos com luas azuis e às mouras, luas de pano azul nos mantos, para que fossem conhecidos e se evitasse erros e pecados. (MACEDO, 2003, p. 8)
\end{abstract}

Nota-se que o Concílio de Valladolid já normatizou a diferença em 1228 apontando a utilização de signos distintivos aos judeus e mouros, inclusive. Porém, trinta anos depois ainda era necessário reafirmar a diferença desse grupo na lei. A repetição, como já dito em outro momento, nos sugere que a lei não estava sendo cumprida, muito provavelmente. Ou, mesmo sendo cumprida, não era tão eficaz como identificação, precisando limitar o consumo de elementos luxuosos para segregar mais os sujeitos. Afinal, a combinação do signo de distinção, somada ao luxo de peças adornadas e tecidos ricos, pode passar uma mensagem conflitante aos demais habitantes, e consequentemente um tratamento inadequado ao personagem.

Resistência de um lado e pressão clerical de outro, considero que tenham sido as motivações para a elaboração desse artigo na ata das cortes de Valladolid de 1258. Ou seja, tentar identificar os judeus na sociedade, sem peças luxuosas disponíveis na 
região e com a abertura para, a qualquer momento, o rei normatizar sobre a inclusão de algum signo distintivo, privando-os da riqueza e da convivência em sociedade.

\section{Mouros}

De acordo com o dicionário Infopédia278 de língua portuguesa, mouros279 são aqueles que seguem o islamismo; muçulmanos; e até, naturais ou habitantes do norte da África. O dicionário Informal de língua portuguesa descreve o mesmo verbete como “é um indivíduo da etnia dos mouros, que é um povo árabe-berbere, que conquistaram a península Ibérica, vindo do Sahara (VIDE SAHARA) e da Mauritânia."280

De modo geral, mouros são povos que se instalaram na Península Ibérica durante vários momentos da Idade Média. O dicionário aponta um povo "árabe-berbere" porque eram os mais conhecidos, porém existiram outros. Até o século IX, logo que conquistados eram aniquilados. Porém, a partir desse momento, eram poupados, com objetivo maior de utilização de sua mão-de-obra de modo escravizado. Em muitas regiões da atual Espanha esse grupo possuía a proteção da monarquia e recebiam alguns benefícios. Suas principais atividades eram no campo da agricultura e do artesanato, 0 que representava parcela significativa na economia região que habitavam. (AZEVEDO, 1999, p. 219)

Assim, temos no artigo 27 da ata das cortes de Valladolid de 1258:

Manda o Rei que os mouros que moram nas vilas que são povoadas de cristãos que andem com a extremidade superior em formas circulares ou o cabelo partido sem topete, e que tragam as barbas longas como manda sua lei, nem tragam cendal nem pena branca nem pano tingido, senão como dito acima sobre dos judeus, nem sapatos brancos nem dourados e o que fizerem que seja a mercê do Rei.281

278 Mouros. Dicionário Infopédia de Língua Portuguesa. Disponível em: https://www.infopedia.pt/dicionarios/lingua-portuguesa/mouro Acesso em 12 de março de 2021.

279Também chamados de "mudéjares" e "mouriscos". Mouriscos é mais utilizado quando batizado e convertido ao cristianismo, porém encontrei em alguns estudos o termo sem essas condições.

280Mouros. Dicionário Informal. Disponível em: http://www.dicionarioinformal.com.br/mouro/ Acesso em 12 de março de 2021.

281Traduzido pela autora a partir das Atas da corte de Valladolid de 1258: "Manda el Rey quelos moros que moran enlas uillas que son pobladas de christianos que anden çerçenados aderredor o el cabelo 
Ressaltamos o fragmento "que tragam as barbas longas como manda sua lei" que permite aos sujeitos homens que levem suas barbas conforme sua religião prega. Considero isso como um certo benefício da monarquia a esse grupo. Além disso, pensamos que tal fato auxilia no aspecto de identificação externa. Assim, a atitude de normatizar dessa forma pode ser analisada como uma via de mão dupla, de modo que agrada aos mouros, por não criar obstáculos a sua fé, e favorece o aspecto de identificação visual e consequentemente de manutenção da ordem social dos habitantes de Valladolid.

O termo "a mercê do Rei" indica que o mouro fique em sua completa dependência. Ou seja, o mouro nesse caso, pode apenas fazer com sua aparência aquilo que o monarca aprovar. Conforme a análise do grupo anterior, aqui existe uma brecha da lei para que seja outorgada qualquer medida sob o argumento de ser a vontade do soberano.

O artigo pretende padronizar também o modo como esses personagens arrumam seus cabelos. Isso nos indica, primeiro, que os mouros levavam os cabelos maiores e de maneira mais diferenciada que os demais habitantes da sociedade. E, segundo, que os cabelos também eram componentes relevantes da aparência pessoal. $E$, terceiro, que não havia uma única maneira de homens e mulheres organizarem seus fios.

Destacamos um fato que Rivair Macedo resume:

Em estudos sobre a vestimenta mudéjar282 nos testemunhos iconográficos
castelhanos da segunda metade do século XIII, como o Livro del Aljedrezz,
dados y tablas de Alfonso $\mathrm{X}$, certos estudiosos tem colocado em evidência o
quanto o traje mudéjar adaptou-se às modas imperantes na sociedade
castelhana, influência tanto maior nas camadas menos aquinhoadas, embora
o mesmo possa ser dito em relação às incorporações mouriscar à
indumentária cristã. Parece-nos que, do lado mouro, a adaptação era o

partido sin copete, e que trayan las baruas luengas como manda su ley, nin trayan çendal nin pena blanca nin panno tinto, sinon como sobredicho es delos judios, nin çapatos blancos nin dorados e el quelofiziere que sea a merçed del Rey."

282"Dito sobre uma pessoa: muçulmano, que seria permitido, em troca de um tributo, viver entre os cristãos vencedores, sem mudar de religião." Mudejár. In Diccionario de la lengua española. Disponível em: http://dle.rae.es/?id=PzaUYdS Acesso em 20 de março de 2021. 
resultado da convivência, mas também do desprestígio que aqueles trajes de origem poderiam representar. Seja qual for o motivo, o fato é que as autoridades estavam atentas e esforçavam-se para marcar o distanciamento que a mudança da indumentária poderia diminuir. (MACEDO, 2003, p. 17)

Apesar dos distanciamentos em tantos âmbitos, os grupos religiosos acabavam absorvendo e copiando alguns aspectos da aparência e vestimenta dos demais. Pensamos que talvez, nesse momento, em que a lei é elaborada e imposta, essas trocas estejam intensas e a identificação visual esteja ficando mascarada. Ainda, aqui se apresenta aspecto crucial do sistema de moda, a emulação e adaptação. Nesse caso especificamente, sobrepujando diversas outras prioridades como a caracterização do personagem de acordo com o seu grupo religioso. A estética, a roupa bela, o adorno chamativo, acaba sendo prioridade em algumas ocasiões.

Destacamos o trecho "senão como dito acima sobre dos judeus" em que o próprio artigo já releva a equivalência entre os judeus e mouros para a sociedade, de modo geral. E ressaltamos o fato de serem iguais as condições de restrição do luxo. 0 que apenas reforça a condição de ambos os grupos como diferentes e marginalizados na sociedade. O que por um lado, afasta ambos da cristandade, e por outro lado, os aproxima no olhar dos cristãos, os dois são marginalizados dessa sociedade.

Os mouros, assim como os judeus, eram símbolos da marginalidade. Afinal, na Europa Ocidental na Idade Média, o fator de diferenciação dos sujeitos, era, primordialmente, a sua fé. (GEREMEK, 1995, p.42). Pontuamos isso para situar que há diferenças, e hierarquia, entre os marginalizados, de modo que os religiosos, eram os mais perigosos à ordem social. Por isso, precisavam levar em sua aparência sinal que os situasse como infamantes. 283

O principal alvo das normatizações aponta para a vida pública desses sujeitos, inicialmente pela necessidade de controle social e pela vigília dos valores cristãos. Desse modo, esses grupos deveriam ser identificados como diferentes, representados do no que se refere ao tratamento de mouros e judeus. Isso tanto nos séculos XIII, XIV, XV. Sobre o tema, indicamos a leitura do artigo: MACEDO, Rivair. Os sinais da infâmia e o vestuário dos mouros em Portugal nos séculos XIV e XV. Bulletin du centre d'études médiévales d'Auxerre, Bucema, Hors-série, n. 2, 2008. 
mesmo modo e tratados de modo adequado a sua condição de marginalizado da fé. É nesse sentido que aparece a utilidade do signo da infâmia, ela permite que desde o primeiro contato visual o personagem seja identificado conforme sua situação.

\section{Considerações finais}

Observamos que um dos objetivos para a elaboração das leis suntuárias foi a criação de um código de aparências, de modo que os sujeitos sejam identificados conforme sua condição social em termos religiosos, econômicos e de sexo. No caso de Valladolid, no século XIII, na lei de 1258, aconteceram normatizações referentes à exclusão daqueles que são exonerados.

De modo geral, pensamos a roupa nos séculos XIII e XIV como uma estratégia social. Ou seja, por meio da vestimenta o sujeito poderia inserir-se em determinado grupo, aproximando o máximo possível sua aparência à do grupo desejado. Desse modo, receberia o mesmo tratamento que todos os pertencentes àquela camada social ou agrupamento. Outra opção era a segregação que acontecia também no espaço da expressão do personagem. Esta consistia em estipular signos distintivos aos grupos que eram marginalizados naquela sociedade.

Ressaltamos que a aparência se distinguia especificamente nos detalhes, as peças de vestimentas e a base das roupas se alteraram pouco de um grupo social para outro. O que se altera e diferencia os perfis são os detalhes, os adornos, os tecidos com que são feitos, as cores e as origens do tecido.

A região de Valladolid, e a península Ibérica como um todo, são palco de guerras por motivações religiosas e territoriais por aproximadamente sete séculos. O que acontece é que durante esses séculos houve períodos de paz, sem batalhas, porém com os grupos protagonistas da disputa habitando os mesmos locais. O resultado é que por mais que sejam opositores, eles interagem cotidianamente e interferem, a longo prazo, na cultura do outro. Percebemos essa influência na linguagem, na alimentação, nas formas de trabalho e também nas vestimentas e adornos. 
Consideramos que era necessário detalhar o código de aparências para manter a ordem social, ou, pelo menos, tentar conter os excessos que atacavam diretamente a manutenção dessa hierarquia. As normas de Valladolid no século XIII, sobretudo para o ano de 1258, aparecem reafirmando a ordem vigente. Nesse sentido, as ameaças que as variações da aparência causavam pareciam ser solucionadas.

\section{Referências bibliográficas}

AZEVEDO, Antonio Carlos do Amaral. Dicionário de nomes, termos e conceitos históricos. 3a. ed. Rio de Janeiro: Nova Fronteira, 1999.

BOUCHER, François. História do vestuário no Ocidente das origens aos nossos dias. São Paulo: Cosac Naif, 2010. p. 164.

BRAUDEL, Fernand. Civilização material, economia e capitalismo séculos XV-XVIII: As estruturas do cotidiano. São Paulo: Martins Fontes, 2005.

CRANE, Diana. A moda e seu papel social: classe, gênero e identidade das roupas. Tradução de Cristiana Coimbra. 2 ed. São Paulo: Editora Senac, 2013.

Criptojudaísmo in Dicionário Informal. Disponível em: http://www.dicionarioinformal.com.br/criptojuda\%C3\%ADsmo/ Acesso em: 05 de abril de 2017.

Diáspora, in Dicionário online de Português. Disponível em: https://www.dicio.com.br/diaspora/ . Acesso em 07 de abril de 2017.

FELDMAN, Sergio. A monarquia visigótica e a questão judaica: entre a espada e a cruz. Saeculum, 17, João Pessoa: Universidade Federal da Paraiba, 2007.

FELDMAN, Sergio. A presença judaica nas cortes medievais castelhanas: de meados do século 13 a meados do século 14. Arquivo Maaravi: Revistadigital de Estudos Judaicos da UFMG. Belo Horizonte, v. 9, n. 16, 2015.

FOGG, Marine. Tudo sobre moda. Rio de Janeiro: Sextante, 2013.

GEREMEK, Bronislaw. Os filhos de Caim: vagabundos e miseráveis na literatura europeis, 1400-1700. São Paulo: Companhia das Letras, 1995. P.42.

HUGHES, Diane Owen. As modas femininas e seu controlo. In: DUBY, Georges; PERROT, Michelle. (dir.). História das mulheres no Ocidente. Vol 2: Idade Média. Porto: Afrontamento, 1990. p.186. 
Judeu, in Dicionário Priberam da Língua Portuguesa. Disponível em: https://www.priberam.pt/dlpo/judeu Acesso em 15-03-2021.

LIPOVETSKY, Gilles. e ROUX, Elyette. O Luxo Eterno. Da Idade do Sagrado ao Tempo das Marcas. São Paulo: Companhia das Letras, 2005.

LIPOVETSKY, Gilles. O império do efêmero: a moda e seu destino nas sociedades modernas. São Paulo: Companhia das Letras, 2009.

LOYN, Henry Royston. Dicionário da Idade Média. Rio de Janeiro: Jorge Zahar, 1990.

MACEDO, José Rivair. Os sinais da infâmia e o vestuário dos mouros em Portugal nos séculos XIV e XV. Flávio de CAMPOS \& Eliana Magnani Soares CRISTEN. Le Moyen Age vu d'ailleurs. São Paulo: Instituto de Estudos Avançados da USP, 2003.

MACEDO, Rivair. A face das filhas de Eva - os cuidados com a aparência num manual de beleza do século XIII. História, São Paulo, v.17-18, p. 293-314, 1998. p. 308.

MACEDO, Rivair. Os sinais da infâmia e o vestuário dos mouros em Portugal nos séculos $X I V$ e XV. Bulletin du centre d'études médiévales d'Auxerre, Bucema, Hors-série, n. 2, 2008.

MARQUES, António Henrique Rodrigo de Oliveira. A sociedade Medieval Portuguesa: aspectos da vida quotidiana. 6 ed. Lisboa: A Esfera dos Livros, 2010.

Mouros. Dicionário Infopédia de Língua Portuguesa. Disponível em: https://www.infopedia.pt/dicionarios/lingua-portuguesa/mouro Acesso em 12 de março de 2021.

Mouros. Dicionário Informal. Disponível em: http://www.dicionarioinformal.com.br/mouro/ Acesso em 12 de março de 2021.

Mudejár. In Diccionario de la lengua española. Disponível em: http://dle.rae.es/?id=PzaUYdS Acesso em 20 de março de 2021.

POLLINI, Denise. Breve história da Moda. São Paulo: Claridade, 2007.

ROCHE, Daniel. A cultura das aparências: uma história da indumentária (séculos XVIIXVIII). São Paulo: SENAC, 2007.

ROCHE, Daniel. História das coisas banais: Nascimento do consumo séc XVII-XIX.Rio de Janeiro: Rocco, 2000. 